\title{
Influence of Network New Media on the Digital Dissemination of Chinese Literature
}

\author{
Xudi $\mathrm{Wu}^{1}$ \\ ${ }^{1}$ Jiangxi Open University,Jiangxi Nanchang,330046,China.
}

\begin{abstract}
The significance and value of literature itself determine the importance of literary communication, and literary text communication contains the communication of literary value and significance. Communication is the carrier of transmitting literary works and the bridge between literature and audience. At present, the network new media has become the most frequently used media platform for the public, providing an independent space for individual information production, accumulation, sharing and dissemination. In this paper, literature communication is defined as "the communication of literary text", taking the literature communication caused by "Wang Guozhen's death" as the research object, through the analysis of the content of relevant information and the questionnaire survey of the audience, the statistics show that the people who get the information through wechat circle of friends are the most, accounting for $33 \%$, and the influence of network new media on literature communication and the reasons for its influence are analyzed.
\end{abstract}

\section{Introduction}

The significance and value of literature itself determine the importance of literary communication, and literary text communication contains the communication of literary value and significance. Communication is the carrier of transmitting literary works and the bridge between literature and audience. The value and significance of literature need the participation of "communication" to play its role. According to the course of literary theory, literary activity consists of four elements: the world, writers, works and readers, and two concrete activities: literary creation and literary acceptance. Literary value is created and realized in literary creation and literary acceptance.

On this basis, according to their own understanding of the external world and the internal world, literary writers semantic this aesthetic perception, form content in the form of language symbols, and create literary texts. The formation of literary language symbols connects the writer and the reader through the disseminator, so that the text reaches the reader. The reader carries on the aesthetic experience and re creation to the literary works, so that the potential value hidden in the literary text finally appears as the real value, and the literary value finally realizes. From the perspective of the evolution of media, literature communication has experienced oral communication, handwritten communication, printed communication and electronic communication. Literature communication has entered the era of network communication. Marshall mclew didn't put forward the idea that "media is information". He thought that media is not only the channel of information transmission, but also the subject that has an important impact on the content of communication, individuals and society. On this basis, we can see that with the evolution of the media, literature itself has given birth to a lot of new text content and form, and because of the changes in literary creation and media, it has impacted the traditional literary industry mode and order, and reconstructed the mode of literary communication. In the era of electronic communication, "radio, film and television, the big electronic media, were born from the end of the 20th century to the beginning of the 20th century, and their development and application were mainly in the middle and late 20th century [2]. Therefore, strictly speaking, the 20th century can be called "the era of electronic media". The use of electronic media is another revolution in the history of literature and art communication, which has epoch-making significance. Now we are in the era of network communication. Through the free and open network platform, writers and works can be directly connected with readers. The platform of literature production and communication has changed from closed one-way to open multi-way. The interactivity of literature communication has been constantly improved, breaking the original mode of literature production and communication. Network literature has become a literature category that can not be ignored, including publishers, publishers and readers Broadcasting and television are no longer gatekeepers, transmitters and fee collectors who control the bridge between literature and readers. Faster means of communication, lower cost of communication, richer interactive ways, the innovation of media technology gives the public a more free and cheap literary communication platform, at the same time, it is 
accompanied by the "lack of information" after the information explosion [3]. Massive network literature text, limited readers' attention, lack of literature communication platform, these elements cause the lack of public information. In the mass of information, the public is bombarded by information all the time, they seem to lose the ability to obtain information to meet their own needs, and more time cost and limited attention are used to deal with excessive redundant information [4].

In order to explore the communication mode of Sinology in the network new media, this paper puts "2015 literature hot events" in the perspective of this study, and selects and refines the research objects according to the research boundary and needs. The "literary hot events" get the wide attention of the audience by forming a public opinion field with wide influence. This kind of attention is not necessarily the audience's active participation in the literary communication, but also the audience's passive information acceptance.

\section{Related Concepts}

\subsection{Literature Communication}

Literature communication is a combination of literature and communication. We can understand it from two perspectives, one is the combination of disciplines, the other is the perspective of literary activities.

From the perspective of discipline combination, literature communication is the combination of literature and communication, which is the combination of two disciplines. On the basis of the original literature discipline research, besides the research on the content and form of literature writing, the style and characteristics of literary writers, the essential process of literary creation, and the related effects of literary texts, the perspective of communication is introduced to provide more abundant information for literature research Rich's theoretical perspective and framework focus on the text carrier and media in literature, as well as the relationship and information flow among various elements in literary activities. At the same time, literature provides a research object for communication [6]. $\quad$ From the perspective of literary activities, literary communication is the process and structure of literary activities. Literary activity consists of four elements of the world, writers, works and readers, and two concrete activities of literary creation and literary acceptance. The operation of literary activities needs to connect the four elements of the world, writers, works and readers into a whole movement. The heart type literary activity itself is the process of literary communication, and literary communication is the bridge between the elements of literary activities [7].

\subsection{Communication Mode}

Morton doich, an American social theorist, points out that a pattern is "a structure of various symbols and operating rules, which is used to connect the existing structure or the relevant points in the process". "Pattern" is essential for understanding more complex processes."
To sum up, the characteristics of the model is to simplify the complex theory or phenomenon, and the role of the model is to show the structure or process of the complex theory or phenomenon in an intuitive and concise form. Therefore, we believe that the so-called model refers to the intuitive and concise description of the internal and external mechanism of objective things, which is a simplified form of theory and can provide people with the overall information of objective things [8].

Models can be divided into two types according to their functions: structural model, which only describes the structure of something; functional model, which describes the relationship and interaction between various systems and elements from the perspective of energy, power and direction. The communication mode is basically a functional mode constructed by words and charts.

According to the concept of mode, generally speaking, communication mode can be regarded as a simplified description of the phenomenon of communication. The current scholars have different interpretations of the concept of communication mode, but they basically explain it from the two dimensions of structure and process [9].

As for the function of the model, Morton doych thinks that the model has four significant functions: organization, inspiration, prediction and measurement. Patterns can organize data, sort and connect data, which shows the relationship between data; patterns can show through structure and process, and develop new unknown facts and methods; a new pattern can help people explain things that they didn't understand in the past and make predictions; if the pattern allows us to make quantitative predictions, it can help people to measure smart objects [10].

\section{Research on the Influence of Network New Media on the Digital Communication of Chinese Literature}

Some media call Wang Guozhen "Guo Jingming of the 1990s", which is based on the popularity of Wang Guozhen's poems in the 1990s. You may not like his poetic style and do not recognize his poetic level, but you must have heard or seen the classic sentences in his poems. Wang Guozhen and his poetry after the tide, with the development of the times, to the tide, until his death, let his poetry once again become the focus of attention. From the rise and fall of the tide to his death, Wang Guozhen and his poems have experienced the changes of the disseminators and media channels of literature communication in the past 30 years, and their communication contents are different with the development of the times.

\subsection{Selection of Research Objects}

As this paper limits literary communication to "literary text communication", in the 2015 literary hot events, only the literary communication caused by "Yu Xiuhua's popularity" and "Wang Guozhen's death" meet this requirement, because they are very similar. After selecting the research objects according to the research boundary 
and needs, this paper takes the literary communication caused by "Wang Guozhen's death" as the research object Other hot literary events are also in the scope of this paper, as a supplement to the investigation and analysis.

\subsection{Investigation Methods}

Through the design of questionnaire, quantitative research is used to measure the audience. From May 4 to 18, 2020, this paper conducted a survey by randomly distributing questionnaires. A total of 211 valid questionnaires were collected. Questionnaire survey was conducted on the media usage habits, the attention and focus on "Wang Guozhen's death", the dissemination of new media on the Internet and the participation in relevant literary activities. On the basis of collecting, sorting and analyzing the data from the questionnaire survey, this paper analyzes the process and effect of literature communication in the era of network new media, and probes into the deep influence of network new media on literature and literature communication combined with qualitative research.

\section{Analysis of Survey Results}

\subsection{Network New Media Channel Investigation}

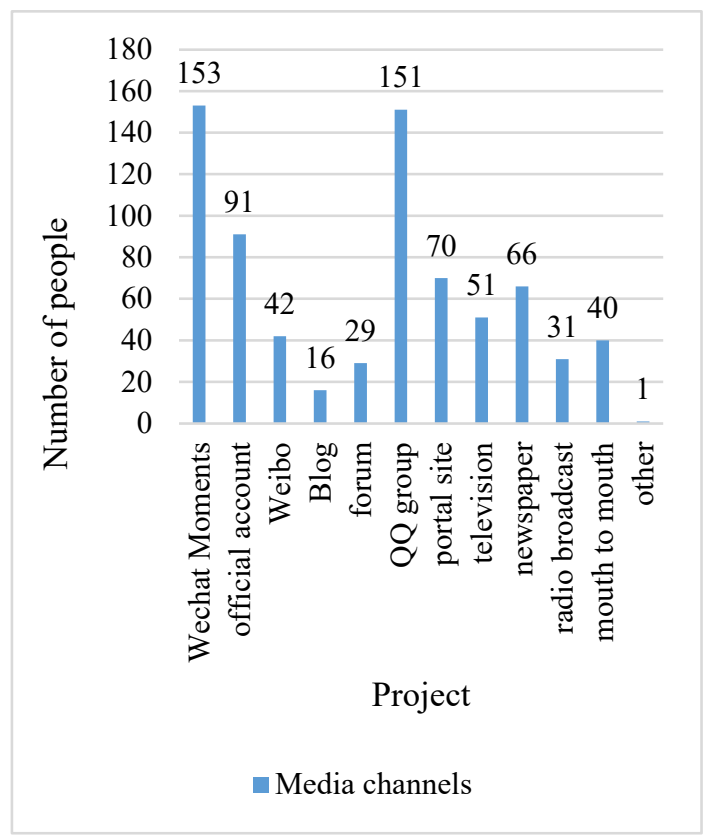

Figure 1. Audience media exposure survey

According to Figure 1, among 210 respondents, 153 people indicated that wechat circle of friends was the most frequently used information media channel, followed by QQ group with 151 people. Because WeChat friends circle and WeChat official account differ slightly in the identity of the communicators, the two parties are listed separately for investigation, but in general, WeChat: 244 people become the most frequently used media. Microblog, blog and forum, which are also new network media, only have 42, 16 and 29 person times. Among the traditional media, the highest newspaper media only has 66 person times, only about a quarter of wechat person times.

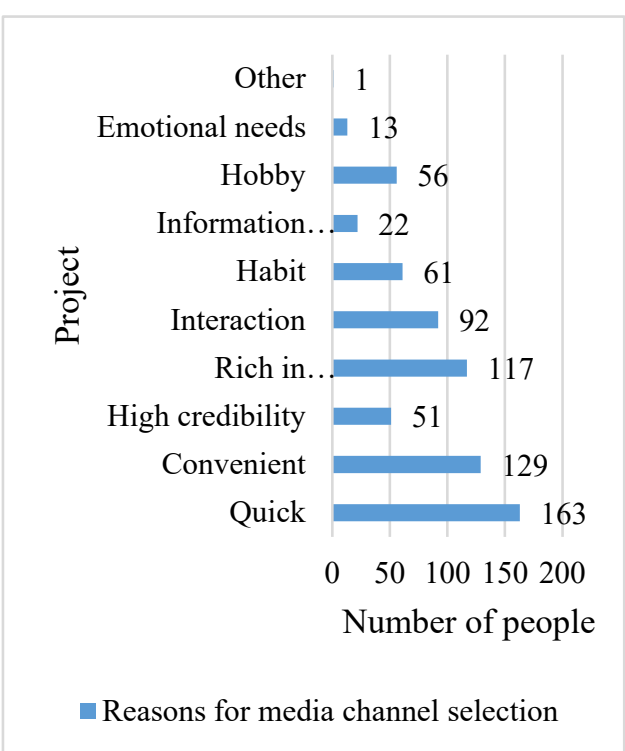

Figure 2. Causes of audience media selection

Based on the formula of "media choice probability", the results of questionnaire survey showed that among the surveyed people, the top three users of the information media platform were WeChat friends circle, WeChat official account and QQ group. In the survey of why to choose this kind of media channel, the top three reasons are the convenience of information transmission, the convenience of media channel contact, and the strong interaction (which can be commented and forwarded). The traditional media's proud credibility and authority are only in the second place, which is not the primary factor for the audience to choose media. Network new media can not only meet the "guarantee of reward" of the audience, but also provide a lower "degree of effort" for the audience. In addition, we should also see that strong interactivity and interest circle communication are the unique advantages of the network new media platform, and the technology of network new media gives people more rich media contact experience. With its own advantages, the network new media communication channel has become the most commonly used information media platform.

\subsection{First Channel Investigation for Specific Events}

Table 1. The first channel for the audience to receive information on the death of Wang Guozhen

\begin{tabular}{|l|c|}
\hline Irrigation ditc & $\begin{array}{c}\text { Proportion } \\
\text { population }\end{array}$ \\
\hline WeChat Friends & $32.83 \%$ \\
\hline Portals & $28.79 \%$ \\
\hline QQ groups & $8.08 \%$ \\
\hline Official Accounts & $8.08 \%$ \\
\hline Weibo & $7.58 \%$ \\
\hline Newspaper & $4.55 \%$ \\
\hline $\begin{array}{c}\text { Human-to-human } \\
\text { transmission }\end{array}$ & $4.04 \%$ \\
\hline Forum & $2.02 \%$ \\
\hline TV & $1.52 \%$ \\
\hline Broadcast & $1.52 \%$ \\
\hline
\end{tabular}


From the survey of the first time that the audience was informed about the incident, the most people who got the information from WeChat circle were $33 \%$, followed by portals, such as Sina, NetEase, Tencent, Sohu and other websites, accounting for $28 \%$; WeChat official account, QQ group and micro-blog all played a fairly good role in spreading, but none of them were over $10 \%$; newspapers, radio, television and other traditional media were below $5 \%$. Television and radio are less than $2 \%$. Under the background of the rapid development of network new media, the traditional media channel is no longer the first communication channel for people to obtain information at the first time.

\subsection{Analysis of the Phenomenon of Digital Literature Communication in New Network Media}

From the perspective of media timeliness, compared with traditional media channels, network new media has the characteristics of instantaneity, which can release information at the first time. Moreover, this kind of information is released through the way of push reminder, and the audience will receive information notice at the same time. As the terminal of network new media mainly takes mobile phone as the main carrier, the audience has the characteristics of receiving information at any time, anytime and anywhere. Therefore, in terms of timeliness, the network new media takes the lead in information dissemination, which can not be compared with the traditional communication channels. From the perspective of media persistence, radio and television in traditional media channels are transmitted in the form of linear transmission, with the shortest time to save information. Newspapers and magazines have a publishing cycle. Although paper carriers can be saved for a long time, information retrieval costs more. Generally speaking, the persistence and timeliness of media are inversely proportional, but because Internet information can be stored and inquired, the persistence and preservation of network new media are also very strong.

In terms of the amount of media information, due to the limitations of newspaper layout and television broadcasting time, the network new media itself has inherent advantages. By using the storage capacity of cyberspace, the information can be sent in a variety and comprehensive way. Although the network platform has more abundant information, compared with the network new media platform, because the main equipment carrier of the network new media platform is the portable smart phone, the network platform is less convenient and easy to contact the media.

From the perspective of audience participation, on the one hand, it refers to the possibility of the audience entering the communication process, on the other hand, it refers to the degree of mobilizing their imagination when receiving the communication content. Due to the limitations of the media itself, it is difficult for the traditional media channels dominated by newspapers, radio and television to have real-time interactive communication with the audience. The Internet technology makes it possible for both sides of the real- time interaction, and this way of interaction helps the audience to better accept media information, enhance the habit and dependence on media channels. The emergence of network new media makes the general public from a single receiver to a communicator, directly into the communication process.

In general, the network new media communication channel itself has a strong timeliness, long persistence, rich information, portability of the carrier, and through the technical advantages to strengthen the audience's participation, which can not only meet the audience's "guarantee of reward", but also provide the audience with a lower "degree of effort". It has become the most frequent communication channel for the public to contact and use, and has become the most popular communication channel It is the first media channel for people to get information. In the traditional communication channels, the time cost and material cost of literature communication are relatively expensive, and the interaction between the two sides is even less. At present, literature communication makes full use of the network new media channels and borrows the media communication advantages of the network new media itself to get more effective communication and more active audience participation.

\section{Conclusion}

The significance and value of literature itself determine the importance of literature communication. In literary communication, communication is the carrier of literary works and the bridge between literature and audience. With the development of media, the communicators, content, channel, audience and effect of literature communication have changed, which affects the process and mode of literature communication. The proposal of "network new media era" is based on the important position of network new media in the present, which has become the media platform with the highest frequency of public use. By virtue of its technological advantages, new media on the Internet provides individuals with an independent space for information production, accumulation, sharing and dissemination. It not only endows the public with communication technology and possibility, but also constructs different modes of literary communication. This paper takes the literary communication caused by "Wang Guozhen's death" as the research object, discusses the characteristics and changes of communicators, communication contents, communication channels, audiences and communication effects in the communication environment of the network new media era. Based on this, this paper describes the current picture of literary communication, and finally constructs the literary communication mode in the network new media era, and finally gives some suggestions In the era of digital media, the influence and reasons of the new network media communication channels on the literature communication.

\section{Reference}

1. Camila Corrêa Matias Pereira, Botti N C L. Suicide 
in the communication of virtual social networks: Integrative literature review $[\mathrm{J}]$. Revista Portuguesa de Enfermagem de Saúde Mental, 2017(17):17-24.

2. Cheng $\mathrm{Y}$. How Social Media Is Changing Crisis Communication Strategies: Evidence from the Updated Literature[J]. Journal of Contingencies and Crisis Management, 2018, 26(1):41-57.

3. Onwuegbuzie A J . Communication Vagueness in the Literature Review Section of Journal Article Submissions[J]. Journal of Educational Issues, 2018, 4(1), 1-2.

4. Sampaio $\mathrm{S}$, Souto $\mathrm{P}$, Vasques F . A review of scalability and topological stability issues in IEEE 802.11s wireless mesh networks deployments[J]. International Journal of Communication Systems, 2016, 29(4):671-693.

5. Bouyer A, Hatamlou A, Masdari M. A new approach for decreasing energy in wireless sensor networks with hybrid LEACH protocol and fuzzy C-means algorithm[J]. International Journal of Communication Networks \& Distributed Systems, 2015, 14(4):400412.

6. Scott N, Goode D. The use of social media (some) as a learning tool in healthcare education: An integrative review of the literature[J]. Nurse Education Today, 2020, 87(13):104-106.

7. Barboza E D A, Bastos-Filho C J A, Filho J F M, et al. Local and global approaches for the adaptive control of a cascade of amplifiers[J]. Photonic Network Communications, 2016, 33(2):194-207.

8. Pan J . Temporality alignment: how WeChat transforms government communication in Chinese cities $[\mathrm{J}]$. Chinese Journal of Communication, 2019(1):1-17.

9. Rezaei F , Hempel M, Sharif H . A novel automated framework for modeling and evaluating covert channel algorithms[J]. Security \& Communication Networks, 2015, 8(4):649-660.

10. Chen W . Internet Use, Online Communication, and Ties in Americans' Networks[J]. Social Science Computer Review, 2015, 31(4):404-423. 